\title{
Transboundary and Redeem: the Internal Mechanism of Contemporary Art Practice and Its Logic
}

\author{
Jing Qian \\ Taizhou University \\ Taizhou, China
}

\begin{abstract}
With the improvement of productivity, human's life attitudes and aesthetic modes have been penetrated and fused in multiple fields, their concepts and trends also have been greatly changed. Transboundary makes the irrelevant, even conflict, opposite elements penetrated and integrated together, and the emergence of transboundary art works just meets this contemporary need. Cross-learning on the one hand promotes the growth of knowledge, enriches our understanding of art and art history, on the other hand it accelerates the identity crisis of art history itself. Based on the connotation of the new era and by combing the logic of contemporary art practice, it is helpful for us to master the art phenomenon in a holistic and systematic way from the perspective of art disciplines, and further it clarifies the internal mechanism of art occurrence, strives to absorb and fuse the real results of modern thought, trying to explore the significance of its existence in a certain level, expecting to promote the prosperity of our art.
\end{abstract}

Keywords-Contemporary Art; transboundary art works; Cross-learning

\section{INTRODUCTION}

Transboundary was rose in Western industrial field as early as 50 s of last century, after 10 years of development, transboundary concept has been gradually penetrated into the Western art world, brought a new possibility to the art field, therefore art is gradually becoming a kind of more inclusive "Big art". The combination of a new life attitude and aesthetic modes makes the contemporary art received a new life in the pessimistic field of "the end of art". It is an art revolution for new spiritual experience realization and the aesthetic needs. In today which advocate differentiation and diversification, the reality conflict of contemporary art development is becoming more and more prominent, which leads to the legal status of the art creativity, vitality and theory is becoming sluggish, and aggravates the dissolution of the classical discourse culture form. Instead is the communications and cooperation of crossfiled, cross-culture in art filed. This kind of art is called "transboundary art". "Transboundary" refers to the crossover between different art categories and artistic styles and other sectors, with their complementary functions to create a change from plane to three-dimensional, from surface to the depth , break all the barriers to find each other's connection, which forms a kind of "free association" or "all things are prepared for me" art production method. This fusion occurred in highend level of various fields, it is everywhere and even become the trend to lead art fashion.
With the improvement of productivity, human's life attitudes and aesthetic modes have been penetrated and fused in multiple fields, their concepts and trends also have been greatly changed. When a cultural symbol can not reproduce an integrated consumer experience, then the interpretation and reproduction of this experience from several cultural symbols together have become a necessity. Transboundary makes the irrelevant, even conflict, opposite elements penetrated and integrated together, and transboundary value is to make the irrelevant, even conflict, opposite elements penetrated with each other, break the imagination of traditional thinking and mode, expand the exhibition space of contemporary art, so that we have new expectations and longings for the artists' creations, transboundary art works just meet this need of contemporary [1]. The advancement of modern technology has brought great opportunities and challenges to contemporary artists. Each discipline is connected with other categories in the extension, and after the grafting produces a more unique and wonderful work. The study of art is inseparable from the familiarity of art practice, society progress has promoted the creation and development of a variety of transboundary art. Practice shows that diverse artistic concepts, mixed social patterns and unique artistic traditions are the important factors for the art to get a new life. Transboundary as a mixed cultural form, lead to the traditional boundaries of art and non-art disappeared, it was internalized by some avant-garde artists into their artistic ideals and lifestyles, and even vague the boundary of art history which resulting in the identify crisis of art itself. The questions of How to combine art and other disciplines, What is art have been questioned and hung up, why art works are art works has become the focus of academic discussion.

\section{SElF Logic Of ART DEVELOPMENT}

Art is one of the important ways in which mankind expresses the inner independent spiritual world. Its logic is the only criterion to know and feel the art world. Artists took "life" as a material for artistic creation, penetrated rational logic and emotional aesthetics in a variety of artistic creation behaviors, and enhanced the artistic culture and human art experience interaction, promoted people to have the new aesthetic experience of "fusion, agent, change". However, the absolute value of art comes from the value standard only for art "artistic logic ". "Artistic logic" is the logic of emotion, is the strong reaction of individual's inner world in a particular historical environment and living condition. For the artist, the 
objects and fragments of daily life are given the realistic texture of art works. The objective logic standard becomes an object that can be remolded and an element of creation, so as to achieve the transfer from "objective expression" to "personal expression "[2]. Art is essentially a creation of emotional mechanisms, and "beauty" (is the artist's inner desire or an emotional void) is the artist's emotional release. Emotion is the inner motive of artistic creation. Artists through various skilled language, material transformation and even destroying objective reality, follow their freedom nature, so as to maximize release their emotions. So that aesthetic imagery often confined to limited, beyond the natural restrictions, and the release of this freedom more thorough, it can cause more people's resonance. The final result of artistic creation is to realize the materialized form of the aesthetic image, that is, the practical activity transforms the result conceived by the artist into materialized form, and form the aesthetic image, and then use some artistic language to realize the final purpose. However, each artist has a set of artistic "beauty" language, suitable for the expression of their emotions, and hit the inner emotional charm strongly to the hearts of viewers, thus completing the cycle of art works from birth to appreciation. The artist uses their eyes which beyond the daily life experience to observe the world, and then use their "unique" ways to show the world. Hegel pointed out that works of art is the crystallization of thoughts and feelings exteriorization. Through the reality of daily life and the infinite diffused fantasy in the brain, the artist solidifies these ideas into certain figurative images, and uses the symbols of these objects to guide the emotional logic that the artist wants to express. It is true that works of art are created in a way that is imaginative free expression, and this imagination is even closer to nature when it creates images at will. Art is no longer a narrow being in the whole civilization of mankind, but a stratum which gradually get rid of the control of external non-artistic factors (religion or politics) and continues to expand to other fields and becomes the a dependent way of human survival.

Artistic logic is active not only in the process of artistic emotion cohesion, in the aesthetic process also plays a decisive role.[3] The aesthetic image is formed by the imagination, but also according to the rational concept. Real aesthetics can not be ended by any form of power, but also has a wild beyond the reality. It uses power to interrogate the power, in the sublated modern rationality process to realize the conversion to free style. The aesthetic source of art comes from people's production practice. Once the aesthetic object presents to aesthetic subject, it becomes an aesthetic object which is gradually formed in practice and has the social aesthetic attribute. The form creation feature of artist is dominant, it use subject - subject model or subject - media - subject mode to establish the relationship between people and people. In art creation, works of art through the integration of various medias, promote the interaction of artistic perceptual and technological rationality to an unknown frontier, achieve the blend and interaction between technology and art, carry out a "revolution" to the traditional art content and ideas. [4]. In contemporary reality, the spirit and willingness and though of "infinite transcendence" designed for the artistic value appears to be isolated and helpless. In the aesthetic process of the big art fusion, art does not exist alone, which is the artistic symbol is no longer a mere object. A single symbol of art can not become a stimulating element to the public. It is intertwined with non - art, confuse and expressed with each other, which makes the art object deviate from the original concept of "object" and become the "event" and "process". Although the aesthetic connotation of modern art has undergone profound changes in the contemporary era, its emotional release force is stronger and more direct, but we can still get unusual feelings from the lines, colors and textures of the art works, which means that the aesthetic object begins to appear in multiple meanings and multiple structures, and people begin to transfer from past linear reading to structural reading. Art has become a psychological satisfaction which person obtained in "panaesthetic" situation, countless activities connected together to constitute a history of continuous acceptance activities. Public's aesthetic taste and life quality also produced more optimized new art under the countless impacts. It is a continuation of artistic life, which brings a fantastic aesthetic experience to human. The permanent pursuit of beauty in art gradually loses the central position of the aesthetic standard, and the eternal concept will lose the pleasure of the changes in time sections. Everything is in evolution, and the evolutionary process can be understood as fashion logic act process. This action is a forward self-push, is the inner requirement to abandon the old me and welcome the new me.

Art and aesthetics together creates human's artistic life, and gives them the possibility to live freely. With the development of the market economy and the development of democratic culture and information technology, the rational characteristics of technology make mankind lose the poetic dimension of spirit. The instrumental world view makes the spirit degenerate into senses, the art is becoming more and more popular in daily lives. [6] The appeal of human for artistic living makes the artistic reality must be improved. Art as the essence of human spirit, it gradually become the spiritual support for human while proving the sense enjoyment to people. Contemporary art is an integral part of human spiritual culture and is also a matter of practice. Modernity takes human's subject freedom as its ultimate goal, is part of modernity, which means that the practical significance of aesthetic modernity becomes more and more important. Contemporary art and contemporary society had the split that can not be bridged, advocating the simple, direct, personalized aesthetic way is replacing the traditional aesthetic status, thus leading to the "boundary" between art categories gradually disappeared and integrated, replaced with the new art formed by transboundary. Contemporary art is produced in the cultural tension between tradition and modernity, between self and others. On one hand, it promoted the principal principle of modernity, and on the other hand, it separates modern rationalization principle as a force of digestion. Contemporaneity is a new sense of time, once the theory defined boundary and standard to the new art form, the art itself is bound to resist the single system, resulting in the action to break the "definition", which constitutes the dislocation of contemporary art language, and the important driving force for continuous self-renewal. At the same time, artistic beauty is not a physical fact, but a psychological fact. The importance of art does not come from if it looks like art or not, or if it has "modernity", but come from whether it can 
reflect the height belongs to a new era based on the "contemporaneity" of today's social life. When contemporary artists create contemporary art works, it shows more on concerns and thoughts about social, historical, human and other issues. And the spread of the artist's ideas is no longer confined to the art circle, this communication need is a result of the change in contemporary artists and social environment, enrich the observe angles so that to make viewers to think not the passive reproduction or deliberately imagination. In contemporary society, innovation and change are the spirits that all areas pursuit, start to explore new goal once complete the old goal, because the future is what we will have to face, history has been behind us, and the process of constantly explore new things also implied the logic of fashion.

\section{RATIONAL INTER VENTION OF ART AND TRANSBOUNDARY}

From the development context of the Western transboundary phenomena, we can see that the reason why the art works can crossover is because the shackles of the scientific delimitation classification and the commonality of the ideas and methods of art creation, which brought us a kind of balance from the limit. Sensibility and reason together to create a human civilization, and the emergence and development of art is also inseparable from the guiding of human rational spirit. The highest realm of Chinese art is natural simple nature and on in one, for art is interlinked and integrated. From the perspective of contemporary art, it seems that nothing can not "be" art, but not everything "is" art. In nowadays which full of new media emergence, the depth integration of technology and art brings people a brand new art level. From a single point of view, transboundary art blend purely sound art, visual images "dance art" rap art and other experimental art together as a "creative crossover", it is a strong resistance for traditional music expression or even the deconstruction of the ontology, and also it is the reconstruction of musical aesthetic thought under the complex semantics. From the perspective of art history, art transboundary from the perspective of subjective reasons can be seen as recontinuation of classical art traditions which was separated by the aesthetic modernity, stimulate from their own internal and formed an unprecedented form of discourse, which provides a kind of art picture of popularized aesthetic. But to be more precisely, it is a kind of post-modernist art concepts and ideas at the same time, it breaks the narrow domain concept of modernist art from talking to itself and mutual differentiation, together with other complex and diverse postmodern ideas and practices constitute the "Anything goes" post-modern culture and art landscape. From its development process it formed an art form variation which suitable with the cultural activities. The artistic "perceptual thinking" establishes the possibility of artistic cross symbiosis, brings artists more creative freedom and space, awakens the subject consciousness, exerts the "new sensibility" and is also a strong response to the secular aesthetics, which has an important significance to adjust the entire social and cultural artistic ecology. Art is a universal language, beyond the boundaries of time and space constraints.

Kant divided art into mechanical art and aesthetic art, and compared art as games. This comes from the fact that game is a display of freedom, from the dual identity of the artist (creator and admirer), and also from it has non-purposiveness and purposiveness. The reason why things are beauty is because the artist can create a world of free domination rely on imagination, which conforms to the concept of the value in view's heart and the nature of human freedom, this requests art with its rational purpose but without revealing any traces. Once the aesthetic need left the aesthetic subject, it lost the power to transfer the inherent power into beauty, and also lost the general prospect which promotes the contemporary art to talk with the public. The aesthetic need is the internal driving force of aesthetic value, and the aesthetic value is closely related to aesthetic need. However, the change of aesthetic psychology of contemporary people is based on the aesthetic logic and idea of contemporary mankind. Behind these "Transboundary" artistic phenomena, the aim is not only to banter and ridicule itself, but the desire for "service" become more alert, profoundly reveals the resistance of "aesthetic" on the whole of modernism and its social manifestations, and this "free game" of art is non-purposiveness and purposiveness [6]. It is the artistic thoughts and creation of social thought and aesthetic needs formed an inner appeal of ideological trend. As far as contemporary art practice is concerned, technology is alienated by society as tools rationally interfered with art. It is not to stifle or deny art, but is an opportunity for true power of art released in contemporary. At the same time, artistic creation must be the art which create artistic images that conform to aesthetic imagery. In the high-grade, precision and advanced science technology era, the development of technology makes the prosperity of new art category, promote the whole art activity more directly into the real life, but also blurred the boundary of art and non-art, life and art, which resulting in the non-materialized art and become the promote force for us to reflect "art" itself.

Contemporary art has penetrated in political field, social activities and all the other aspects, under the strong support of irrational philosophy, moral judgments gradually give way to interest judgment, with a distorted, illusion way of thinking. At the same time, artists group who previously been sponsored by the royal family or aristocracy were slowly spreading in commercial art and became a strategic means for those politics to enhance the value of other things in the real world. The constant expansion of instrumental rationality gradually evolved art into a machine which is playing along and disassembled. Things which originally has nothing to do with art, with the formal beauty of art, spiritual influence and aroused social effects, expressed as an untrue, mixed with a variety of colored lie. However, because of the involvement of commercial capital, the original intention of art transboundary is sometimes not entirely out of artistic considerations, art has become a strategic means of packaging things, this idea has become an important way to achieve innovation. [9]. But these people are not all artists, most of them are a group of "preachers" and "spiritual product maker". Contemporary art has its own production logic, this logic of artistic ideas content transform determined the transform degree of sensible form. It is this kind of omnidirectional interactive logic that forms a new artistic experience, thus enriching the aesthetic characteristics of modern art. The independence of modern art is not only manifested in the differentiation of art and other 
fields of human values, but also inevitably turned to technology, the boundaries inside art are increasingly obvious. Art transboundary in addition to meet the business will, could it realize the transboundary application in the real concern area? Contemporary art language pushes art into an unprecedented diversified development period, art is no longer a single direction, the artist's study object is no longer a purely artistic concept, it relates to the media, production, products, and also relates to the relationship with popular culture and social context. There is an independent play space and the concept form but also have openness and compatibility with other disciplines.[9] In the field of social care and assistance also calls for the intervention of an artistic force, art has become a special impetus to support people out of the darkness. Art goes beyond the connotation of aesthetics and creativity itself, into a higher level spiritual field to help to soothe, to heal the pain of society, to expand the time and space constraints of rational art, to achieve a function to comfort mind and offer assistance, furthermore it also makes art works with time and space continuity.

\section{THE SELF-REDEMPTION OF CONTEMPORARY ART}

Hegel in "Aesthetic Lecture Notes" pointed out that when the "inner concept" beyond the "external form", "reason" expelled the "sensibility", "thinking" occupied the "art", the real art exhausted all the possibilities and toward the end. If art want to get rid of the fate of art end, first of all is to restore its vitality. Based on this, the contemporary art "man" seems to get more freedom and respect, and gradually get rid of the past external non-artistic factors (religious or political) control, find out the legal basis from the art itself, which find out the philosophical basis for contemporary art's "anti-tradition, focus on self ". As far as the internal logic of art is concerned, the nature of art is pure creation or innovation. Innovation thus becomes the basic duty and the survival stronghold for art and artists. The human spirit scale and technical scale are the new measure scale of whether the art is innovative.[9] As to the artists who take art as their "home", whether they can be innovative related to the artistic value and social value of their works, and even become the essential power of them as artists. "Art" to become the true sense of art, it must bear the heritage and development of art life spirit, to reveal the human art activities which take creative activities in spirit field as the main body, to show the inner world with the most sincere patterns. "Being" is the kind of power that makes all things exist, the self-affirmation of "existence" is a pursuit to overcome the threat. "Existence" is life, is continuous, and is creative, which means breaking the boundaries between traditional art categories. It is bound not to remain in the productive stage of human activity, it needs to constantly go beyond itself to be demonstrated and purified. The real strict meaning of "pure art" need to "travel", the direct result is the separation between art and non-art, "art" and "technology". The change of whole concept of contemporary art is the key to the realization of public dialogue, if there is no such separation, still it can not have the daily life aesthetic generalization. Over the past decade, western contemporary art in addition to continue the free exploration of various forms, some mainstream artists are returning to the life nature and spiritual nature of art, and re-examining the eternal value of human beings. Western art and culture has more complete systems in philosophy and aesthetics, and has its own set of framework. But we can not simply and superficially copy it. We should reflect, practice to find the connection between the original culture and contemporary art, find out the Chinese expression of contemporary art, and cast out elite culture and folk culture these two elements of the spiritual core from the deep level.

Society is no longer a unified centered structure, the new set social structure makes people no longer limited to the control of one idea. In the concept of diversity and divergence is the trend of the times forward, the art will also take advantage of this trend to get development. Art as a "skill" since its inception, was used as communication, recording, teaching tools. Many people around us can skillfully use this set of art logic to express their emotional intentions, some people even could use them to obtain great commercial interests. Art without innovation then means no development, transboundary is a very important aspect for art innovation. From the development of art, there are many traditional art categories, due to the lack of innovation in contemporary society, slowly to decline. If blindly emphasize the art inheritance, it can only lead to the demise. The artist's creation is not the imaginary nothingness, artistic inspirations are existing in real world and are perceived by people, his thoughts and actions are influenced by all things from out world together, he feels and understand during the contact and gradually form a unique self, so the artist as a creative subject is real exist.[10] Since art creation must absorb nutrients from the social and cultural environment, then fashion as the field which has contemporary high-profile and far-reaching influence, has provided fashionable and dynamic elements for artistic creation. Contemporary art is not only the carrier of function, but also the carrier of contemporary society and culture. In today's era, especially in the consumer age, art can not pay attention to its own moral uplift, this value can bring consumers a sense of status, identity and happiness. This artistic creativity does not discard the traditional essence, but integrate and fuse a variety of traditional art elements through some ways. Today's society is a consumer-oriented society in which the supply of goods goes far beyond the demand. Commodities are increasingly endowed with cultural connotations of taste, identity and status. Consumption is a stimulated and fulfilled desire, which give people the satisfaction of self-esteem and false feelings of freedom. As a result, the external formal beauty of goods and the inherent cultural taste have become a popular psychological appeal. For that an increasing number of commodity production together with art to strengthen the mutual affinity between the public and art. As a "transboundary" form of art and under the erosion of the logic of consumer culture, the art of consumerism era has been out of the "ivory tower" and into the "ordinary people's home", "art for art's sake" can no longer become the only accurate art mark in contemporary aesthetic culture filed, the boundary between art and life gradually being smoothed. [12] In real life, what we can really see is not the real artistic transcendence, the ultimate meaning of artistic life is "crossing-over" to artistic activities and artistic experiences. 


\section{CONCLUSION}

In the context of globalization, the pursuit of transboundary art is not to pill up with art forms or to make a complex list of content, but the innovation of artistic expression, reflecting the art soul from creativity. "Transboundary" not only could create a more comprehensive creation angle for contemporary art, the mutual penetration between multi-dimensional integration will inevitably make the public concept change. Use the transboundary complementary function to create and present a sense of three-dimensional and depth, in endless creative achievements, the artists fully feel the endless charm brought by the randomness of materials. Technology transfers the subjective perception into reality, which means that art works with single cultural trait have more choices or even temptation. Art transboundary in the post-modern cultural landscape, as a mixed cultural form is intensified, and even internalized by some avant-garde artists as their artistic ideals and lifestyles. Art is the case, during its development process, it crashes, communicates, and fuses with the various ideological trends or concepts in reality, while it is injected with new concept, and it also influences other concepts. Transboundary behavior is the realistic expression of art concept expansion. After all, transboundary is process to complete itself, it's just no longer attached to a certain technology or limited to a certain form, art began to return to life, return to the simplest and purest state. The development process of human art can be seen as the process of art "travel" to art "return", which is mainly embodied in the state that art first integrates with human daily life and continuously purifies itself until the separation with technology, left the non-art and "travel", To the contemporary, technical had re-involved in the arts and realized the "return" back to human's daily life. The art "travel" and "return" obtained a high degree of recognition of human existence, provided rationality and legitimacy for the construction of human art, opened a new vision field of life world art and aesthetic activity. This art transboundary phenomenon has its rationality and inevitability, which promote the emergence of more creative arts and artists. It is one of the most important ways to improve people's life quality after the society enters consumption age.

\section{REFERENCES}

[1] Xia Yanjing: "Exploration on Inductive Logic and the Construction of Chinese Classical Art Theory System", "Art House" 2013 the 3rd issue.

[2] Sun Aijing: "Discussion on the logical intermediary of aesthetic nature ", "Henan Social Sciences" 2015 the 7th issue.

[3] [US]Barron Levis, Cliff Naase, Lu Dachuan Translation. "Media Equivalence", Shanghai: Fudan University Press, Published in 2001.

[4] Hu Xia: "Discussion on the emotional logic law of art language", "Social scientists" 2015 the 6 th issue.

[5] Xu Zihan: "Art's self-integration - discuss the construction logic of artistic creation from the art form of transboundary art works", "Journal of Nanjing Agricultural University (Social Sciences)" 2015 the 5th issue.

[6] Qiu Zhijie: "Cultural Logic of New Media Art (excerpt)", Beijing: Renmin University Press, 2004.

[7] Yang Bin: "Consumer culture and artistic innovation", Nan Lv: Jiangxi Fine Arts Publishing Company, published in 2004.

[8] [US] Jameson: "Postmodernism and Cultural Theory", Beijing: Peking University Press, published in 1997.

[9] Yue Luping: "Artistic Limit War", "Art Review" 2012 the 1st issue.
[10] Ma Lingyan: "Cultural thinking of art and brand transboundary under contemporary social context", "Art House" 2015 the 1st issue.

[11] [Norway]Lars Svenderson, Li Man Translation: "Fashion of Philosophy Beijing", Peking University Press, published in 2010. 